SITING HAZARDOUS FACILITIES: LESSONS FROM LNG

Howard Kunreuther and John W. Lathrop

International Institute for Applied Systems Analysis, Laxenburg, Austria

RR-82-36

November 1982

Reprinted from Risk Analysis, volume 1(4) (1981)

INTERNATIONAL INSTITUTE FOR APPLIED SYSTEMS ANALYSIS

Laxenburg, Austria 
Research Reports, which record research conducted at IIASA, are independently reviewed before publication. However, the views and opinions they express are not necessarily those of the Institute or the National Member Organizations that support it.

Reprinted with permission from Risk Analysis 1(4):289-302, 1981.

Copyright $\odot 1981$ Society for Risk Analysis.

All rights reserved. No part of this publication may be reproduced or transmitted in any form or by any means, electronic or mechanical, including photocopy, recording, or any information storage or retrieval system, without permission in writing from the copyright holder. 


\section{FOREWORD}

The International Institute for Applied Systems Analysis has undertaken a study of the use of risk analysis in siting liquefied energy gas facilities in four countries: the Federal Republic of Germany, the Netherlands, the United Kingdom, and the United States. The work on which the present paper is based was part of this larger study.

The authors of this paper have devised a descriptive framework for the issues raised by siting large-scale technological facilities, and have illustrated its concepts by applying them to an LNG siting process in California. They also suggest ways of using analytical methods to improve both the interaction process among the interested parties and the outcome of the siting debate.

Their ideas are in the spirit of the research that IIASA is presently carrying out on the role of analysts in the policymaking process. Thus, this paper not only contributes to the Institute's work on the problems of risk but also has somewhat broader implications.

ALEC M. LEE

Chairman

Management and Technology Area 


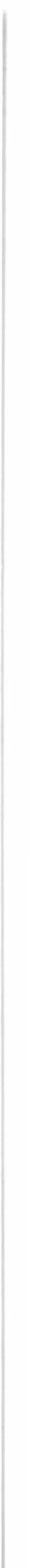




\title{
Siting Hazardous Facilities: Lessons from LNG
}

\author{
Howard Kunreuther ${ }^{1}$ and John W. Lathrop ${ }^{1}$
}

Received February 9, 1981 - Revised November 30, 1981

\begin{abstract}
This paper develops a descriptive framework for siting large scale technological facilities such as liquefied natural gas (LNG) terminals, and suggests ways of using analyses to improve the process. A key feature of these problems is that they involve relatively new technologies where there has not been a long history with which to construct a statistical data base. Hence the interested parties will each have different estimates of the probabilities and losses associated with events that affect the environment or safety of the population. The decision-making process can be characterized as a sequence of decisions, subject to change over time, which are influenced by exogenous factors and new legislation. Each of the separate decisions involves an input phase and an interaction phase. The input phase specifies the relevant alternatives and attributes associated with a particular decision. The interaction phase focuses on the nature of the conflicts between the different parties in evaluating the alternatives. Conflicts are often difficult to resolve because each stakeholder in the process has his own objectives, a limited information base shaped by these objectives and scarce computational resources. We illustrate the above descriptive framework through a case study of the LNG siting process in California. The paper then explores possible ways of improving the input and interaction phases through more structured analyses. Specific attention is given to the role of decision analysis, the analytic hierarchy process, examining assumptions, and the use of interactive computer models for scenario generation. The paper concludes by suggesting future research needs on tesigning policy instruments for helping to reconcile conflicts between the vying interest parties. Promising areas for more problem-focused research include the role of insurance and compensation schemes.
\end{abstract}

KEY WORDS: Siting; decision processes; conflict; use of analysis; low probability events.

\section{INTRODUCTION}

Society has become increasingly concerned with the appropriate procedures for evaluating projects which promise to yield long-run benefits, but also create potentially catastrophic consequences. Recent examples of such problems are the siting of energy facilities such as nuclear power plants or liquefied natural gas (LNG) terminals.

This paper has two principal purposes. Utilizing recent theoretical and empirical contributions to the literature on choice under uncertainty, it proposes a descriptive framework as to how such decisions are reached in the United States. On the basis of this descriptive model, suggestions are made for improving the process. The paper thus is designed to integrate descriptive aspects with prescriptive recommendations.

Section 2 details the elements of a descriptive framework for siting large-scale facilities. A key feature of the process is the interaction of interested parties, each of whom have specific goals and objectives, a limited information base shaped by these objectives, and scarce computational resources.

Section 3 illustrates the framework with empirical evidence from the LNG siting decision process in 
California which has been studied extensively [see Ahern, ${ }^{(1)}$ Deutsch, ${ }^{(2)}$ Linnerooth, ${ }^{(3)}$ and Lathrop $\left.{ }^{(4)}\right]$. Section 4 indicates how we might improve the current decision procedures, recognizing that the political decision-making process is based on a number of institutional and legal constraints which may be difficult to change. The concluding section suggests future research needs with respect to developing policies for reconciling differences between interested parties in the siting debate.

\section{A DESCRIPTIVE FRAMEWORK OF SOCIETAL DECISION-MAKING PROCESS}

\subsection{Relevant Concepts}

In contrast to most textbook analyses of decision making under uncertainty, where there is a well-specified set of probabilities of certain events occurring and potential gains or losses from them, the problems discussed in this paper involve more fundamental uncertainties. For one thing, there has not been a long history with which to build a statistical data base. The technologies are relatively new and in many cases past experience provides us with limited guidance as to the chances of severe accidents occurring. In a similar vein one has to speculate as to what the losses might be should a particular catastrophic event occur in a given location. These two elements of uncertainty represent a challenge for both risk analysis and decision-making.

On the analysis side there is a need to systematically estimate probabilities and consequences from both past data and judgmental studies. There is an extensive literature from controlled laboratory experiments over the past decade which have uncovered a set of biases and heuristics that individuals utilize in dealing with low-probability events [Fischhoff, Slovic, Lichtenstein, ${ }^{(5)}$ Tversky and Kahneman $\left.{ }^{(6)}\right]$. Other studies have suggested that the context in which a problem is framed plays a key role in how people make their decisions [Tversky and Kahneman, ${ }^{(7)}$ Hershey, Kunreuther, and Schoemaker $\left.{ }^{(8)}\right]$. These findings, partly due to computational limitations on the part of individuals, present a challenge to the analyst who would like to improve the decision-making process.
An attempt in this direction has been taken by Fairley ${ }^{(9)}$ who provides a detailed set of guidelines for estimating "small" accident probabilities based on a consideration of catastrophic risk analyses for LNG marine transportation. His motivation for suggesting systematic analyses is that there is a great danger that many sources of an accident will otherwise be omitted. In addition, there are numerous opportunities for bias with respect to judgmental estimates of accident probabilities when there is not a long history of past events. Similar reasoning would apply to the analysis of losses from a given accident, such as a major breach of an LNG tank.

On the decision-making side, the lack of a detailed data base implies that different interested parties will have different estimates of the probabilities and the losses that guide their own judgments. We will look at the process in terms of a scenario involving a number of different decisions, which taken together resolve a particular problem. Some of the decisions may be solved in parallel by different parties; others may be dealt with sequentially.

The decentralized and sequential nature of the process are key concepts which guide the descriptive framework. March ${ }^{(10)}$ characterizes this process as one of limited rationality, whereby individuals and groups simplify a large problem into smaller pieces because of the difficulties they have in considering all alternatives and all information. Support for these concepts at the level of governmental, firm, and consumer decision-making comes from several quarters. Lindblom ${ }^{(11)}$ and Braybrooke and Lindblom, ${ }^{(12)}$ emphasize the incrementalism in decisions made by bureaucracies where there is a tendency for government agencies to "muddle through" by making small changes from the status quo rather than attempting to structure and solve a larger problem. Cyert and March, ${ }^{(13)}$ in their classic study of the behavorial theory of the firm, demonstrate empirically that organizations decentralize decisions and attend to different goals and objectives at different times. Bettmann ${ }^{(14)}$ integrates findings from a number of studies on consumer choice which suggest that individuals simplify the decision-making process by decomposing the problem, utilizing limited search and behaving sequentially with appropriate feedback loops.

Another important concept, which also relates to the uncertainty of information on probabilities and losses, is the importance of exogenous events in in- 
fluencing the decision process. Random events, such as disasters, play a critical role in triggering specific actions to "prevent" future crises. The small data base for judging the frequency of low probability events, coupled with systematic biases of individuals in dealing with concepts of chance and uncertainty, increase the importance of a salient event in the decision-making process. Tversky and Kahneman ${ }^{(15)}$ describe this phenomenon under the heading of availability, whereby one judges the frequency of an event by the ease with which one can retrieve it from memory. The importance of past experience in influencing insurance purchase decisions against low probability events [Kunreuther et al. $\left.{ }^{(16)}\right)$ reflects this characteristic of human behavior.

March and Olsen ${ }^{(17)}$ suggest that random events and their timing play a critical role in many organizational decisions because of the ambiguity of many situations and the limited attention that can be given to any particular problem by the interested parties unless it is perceived as being critical. They provide empirical evidence to support their theory using empirical studies of organizations in Denmark, Norway, and the United States.

In a similar spirit Holling ${ }^{(18)}$ summarizes empirical evidence on how unexpected events played a role in the institutional response to environmental problems. Studies in five different areas of social or economic importance reveal that specific events (e.g., the destruction of forests by an outbreak of the spruce budworm) frequently generate surprise and trigger specific policies designed to cope with the resulting negative outcomes.

With respect to legislative decision making, Walker ${ }^{(19)}$ notes the importance of graphically and easily understood evidence of trouble as an importance factor in setting the discretionary agenda of the U.S. Congress or a government agency. $\mathrm{He}$ also suggests that the political appeal of dealing with a specific problem is increased if it has an impact on large numbers of people. To support these points, Walker presents empirical evidence on the passage of safety legislation in the U.S. Numerous examples of this process are also provided by Lawless ${ }^{(20)}$ through a series of case histories of problems involving the impact of technology on society. He points out that frequently:

New information of an "alarming" nature is announced and is given rapid and widespread visibility by means of modern mass communications media. Almost overnight the case can become a subject of discussion and concern to much of the populace, and generate strong pressures to evaluate and remedy the problem as rapidly as possible. (p. 16)

In the case of decisions such as the siting of facilities, random events such as an LNG fire or oil spill may be sufficiently graphic and affect enough poeple to generate surprise and cause a reversal of earlier decisions, inject other alternatives into the process and change the relative strength of parties interested in the decision outcome. The mass media may play a critical role in focusing on these specific events and in many cases exaggerating their importance.

\subsection{Model Formulation}

The concepts discussed above have motivated the following descriptive framework of the facility siting process. A scenario consists of a sequence of decisions $\left\{D_{1}, \ldots, D_{n}\right\}$, which have to be made by different interested parties. In focusing on any particular problem, it is necessary to specify what the $n$ different decisions are that comprise a particular scenario. For example, Lathrop ${ }^{(4)}$ and Linnerooth ${ }^{(3)}$ have constructed a detailed flow diagram of the different decision points with respect to the siting of the LNG terminal in California. Here the process begins with the Western LNG Terminal Company filing an application with the Federal Power Commission (FPC) for terminal facilities. It continues through a set of interactions between federal, state, and local governmental agencies, special interest groups, and the Western LNG Terminal Company. In the case of nuclear power plant licensing decisions, Jackson and Kunreuther ${ }^{(21)}$ have constructed a scenario which emphasizes the decentralized nature of decisions by separate divisions of the Nuclear Regulatory Commission. The performance of a plant under a series of predetermined accident scenarios is a basis for the final decision as to whether or not to approve a power plant.

These two examples suggest that, although one can look at a particular decision in isolation, it will be integrated with other actions by being dependent on earlier decisions (e.g., the case of LNG siting) or by being integrated at a later stage with other decisions which are made independently of it (e.g., the licensing of nuclear power plants). 


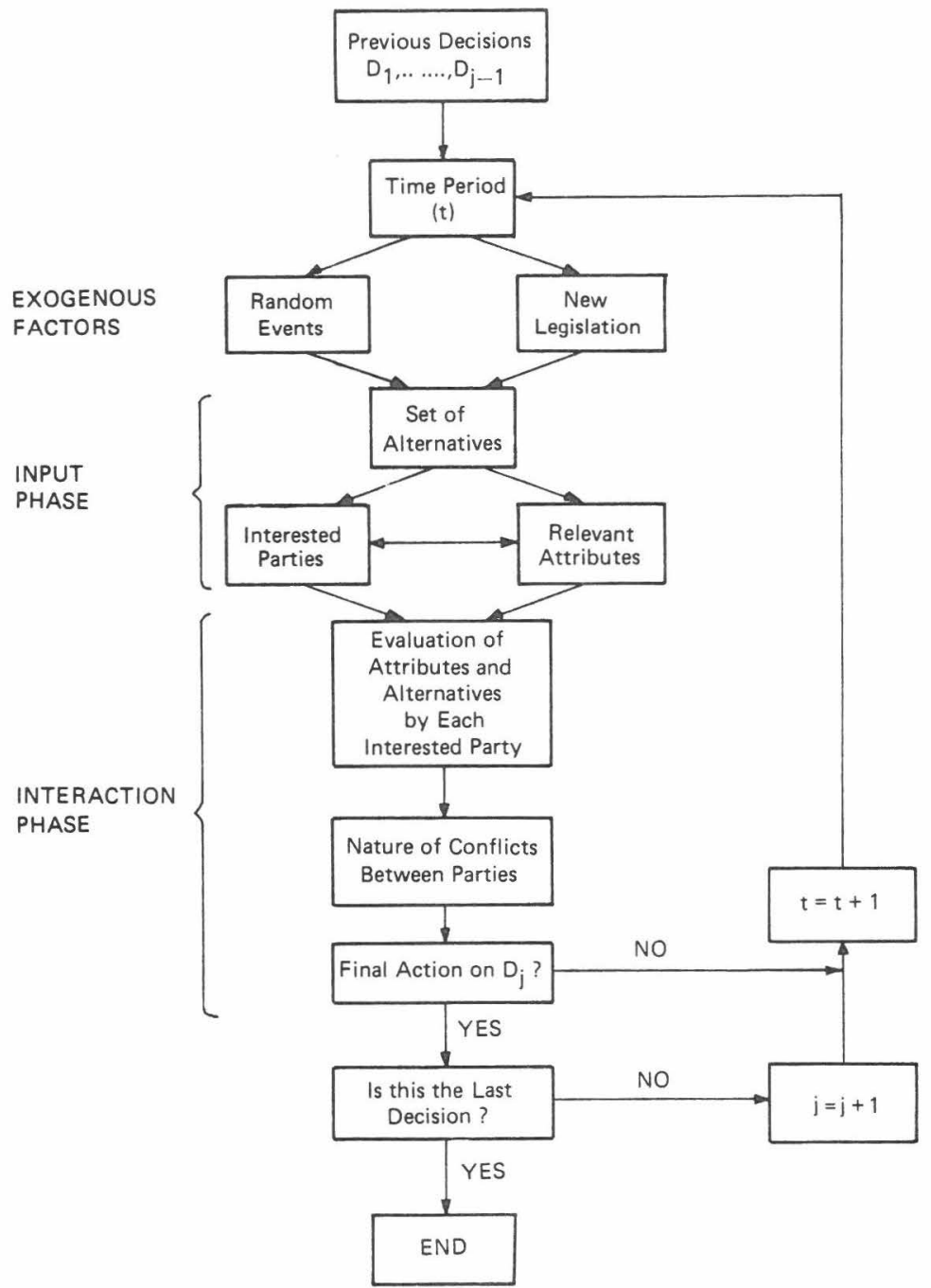

Fig. 1. Descriptive model of choice for decision $D_{j}$.

Consider a particular decision, $D_{j}$, (e.g., whether or not an LNG terminal is acceptable with regard to population risk), which is part of an overall scenario. Figure 1 depicts the relevant aspects of the process. ${ }^{2}$ At any time period, $t$, there are a set of exogenous factors which limit the set of alternatives for consideration. For example, a disaster may trigger specific legislation which provides restrictions on where a hazardous facility can be located. For each set of alternatives there are interested parties who enter the area. One set of alternatives then can determine the

\footnotetext{
${ }^{2}$ A more structured model for the siting process has since been developed at IIASA and is discussed in Kunreuther, Lathrop and Linnerooth (38).
}

attributes (e.g., number of lives lost from an LNG fire) which are considered important by at least one of these parties. In Fig. 1 we refer to the relationship between these three components as the input phase of the process. Thus if one changes the composition of parties as well as the alternatives, one will also change the relative importance of attributes. For example, if special interest groups are concerned with a particular site, then the safety factor may be treated as much more relevant than if these parties do not have an input into the final decision. Similarly if certain attributes are specifically introduced into the picture by one of the interested parties, then this may cause other groups to play a more active role in the process. For example, if the federal government suggests the 
critical importance of safety factors as part of the siting decision, then concerned citizens may unite to prevent their community from being chosen as a site.

Each interested party is likely to have a different set of attributes that they consider to be important to the particular problem. Furthermore, there is no guarantee that two interested parties who focus on the same attribute will measure it in the same manner. For example, public interest groups concerned with the safety of potential sites may have a different estimate of the number of lives lost from a severe accident than the gas companies or the consortium proposing the project. Over time the nature and importance of these attributes may also change due to exogenous factors and a new set of alternatives.

When it comes to the interaction phase, stakeholders are likely to evaluate different alternatives by looking for satisfactory options rather than trying to find an optimal solution [Cyert and $\mathrm{March}^{(13)}$ ]. For each decision $D_{j}$ there may be some level of a particular attribute that is deemed satisfactory, but that level may differ between interested parties. For example, public interest groups may specify an acceptable level of risk to be lower than the gas company proposing the project. As a result these two interested parties may have differing views on the acceptability of alternative sites even if they agree on the chances of an accident. When such conflicts occur, they may cause long delays in reaching a final decision because of the difficulties in resolving conflicts based on value differences. Eventually they may be resolved through some form of consensus by the interested parties, by court rulings or by governmental bodies with specific legislative powers to settle the controversy. For some problems no resolution may take place and the status quo is maintained.

Looking at the interaction phase depicted in Fig. 1 , a central component is the nature of the conflicts between parties. If no final action is taken on a particular decision during period $t$ because of a failure to resolve certain conflicts, this is treated schematically as postponing action until the next period. In period $t+1$, a set of exogenous events may occur that substantially change the situation. The breach of a storage tank or the discovery of an earthquake fault may reveal certain features of facilities or sites which may make them unacceptable. These exogenous events may change the relative importance of different interested parties and attributes. In addition, the events and the public's reaction to them may trigger new legislation which deem certain previously satisfactory alternatives unacceptable and force a reevaluation of earlier decisions $\left\{D_{1}, \ldots, D_{j-1}\right\}$.

To summarize, there is a set of decisions which have to be made over time as part of a scenario for a particular problem. There are laws and regulations which guide the acceptability of specific alternatives and there are different interested parties involved in the process. Because of the uncertainty regarding the probability and potential impacts of catastrophic events, interested parties with different goals and objectives and with limited computational capacities may have different estimates of the risks associated with specific actions (e.g., the siting of an LNG terminal at a particular location). Furthermore, random events can have a major impact on the decisionmaking process by triggering new legislation which may change the set of alternatives, relevant stakeholders and attributes for consideration. Conflicts between these parties can lead to lengthy delays.

\section{THE LNG SITING DECISION IN CALIFORNIA}

The above descriptive framework outlined in Fig. 1 will be illustrated here by analyzing the decision process associated with siting an LNG terminal in California. This description will reveal implications of the structure of such a process concerning societal decision making for low probability events. We will first describe the nature of the problem, delineate the relevant interested parties and attributes perceived to be important, comment on the implications of this structure, and then discuss the role of exogenous events on the decision process.

\subsection{Nature of the Problem}

Liquefied natural gas (LNG) is a medium for transporting energy that has the potential, albeit with very low probability, of creating severe losses. To transport natural gas over long ocean distances it has to be converted to liquid form at about $-160^{\circ} \mathrm{C}$ and $1 / 600$ the volume. It is then shipped in specially constructed tankers and received at a terminal where it undergoes regasification and is then distributed. The entire system (i.e., the liquefication facility, the LNG tanker, and the receiving terminal and regasification facility) can cost more than $\$ 1$ billion to construct [Office of Technology Assessment ${ }^{(22)}$ ]. The 
siting problem of interest consists of two principal decisions: whether the proposed LNG project is in the best interest of society in terms of its impact on the future U.S. energy mix $\left(D_{1}\right)$, and if so, whether the proposed site is appropriate in terms of meeting specific safety, environmental and economic criteria $\left(D_{2}\right)$. Note that the alternatives for $D_{1}$ are whether or not to have an LNG project, while those for $D_{2}$ relate to proposed terminals at specific sites.

\subsection{Interested Parties and Relevant Attributes}

There is a set of interested parties associated with each of the above two decisions. Some of these parties are specified by law (e.g., government agencies), others play a role because of specific concerns with the hazard (e.g., public interest groups), and others because of their economic interest in the project (e.g., gas companies). In the case of $D_{1}$, there are three principal stakeholders, each of whom considers different attributes as important. The gas company or the consortium proposing the project considers such attributes as gas price and capital base as they affect its financial position, degree of control over the source, and supply security.

The second party is the Department of Energy (DOE), which must ascertain whether the project is in the national interest. ${ }^{3}$ Two agencies within the DOE are involved: the Federal Energy Regulatory Commission (FERC), which rules on site and project suitability, and the Economic Regulatory Administration (ERA), which evaluates economic aspects of the project and its effects on national energy supply security. Among the principad attributes that these two agencies are supposed to consider are the security of supply, the proposed LNG price in relation to the price of alternative supplies, impact of the price schedule on conservation of energy, and whether the proposed site meets safety and environmental requirements as stated in any national guidelines. $\left[\mathrm{DOE} / \mathrm{ERA}^{(23)}\right]$. The third principal party involved in $D_{1}$ is the California Public Utilities Commission (CPUC), which has responsibility at the state level for issues similar to those considered by DOE at the federal level.

In addition to these three parties, other agencies set safety standards for all proposed LNG projects.

\footnotetext{
${ }^{3}$ Prior to 1977 this responsibility resided with the Federal Power Commission (FPC).
}

The Office of Pipeline Safety Regulations (OPSR), is responsible for the landward side of the LNG terminal, while the Coast Guard has jurisdiction over the marine side of the terminal, including ship movements and the portion of the LNG system that connects the tanker to the storage system.

The site-specific decision, $D_{2}$, involves some of the same parties as $D_{1}$, as well as additional groups. The set of relevant attributes are likely to differ from the ones related to the first decision. For example, the gas company now focuses on site-specific costs, accessibility of tankers, and where appropriate landuse and environmental factors [OTA $\left.{ }^{(22)}\right]$. The FERC examines site suitability with particular attention to environmental impacts and safety.

Before 1977 the city and county governments had responsibility for evaluating local impacts of a project, while at the state level the California Coastal Commission (CCC) ruled on the impact of a particular site on the environment with special sensitivity to preservation of coastal natural resources. These agencies were required to hold public hearings in which all the parties had a chance to be represented, including special interest groups and local citizens groups concerned with safety and environmental impacts. The California LNG Terminal Siting Act of 1977 essentially removed local authority and centralized the state approval authority in the CPUC, changing the $\mathrm{CCC}$ role to determining a ranking of alternative sites.

\subsection{Implications of the Decision Process Structure}

The current LNG siting process illustrates two key features of multiparty societal decision processes. First, the decision is disaggregated in such a way that each agency focuses on a subset of all the attributes in comparing different sites. For example the CCC, which has a responsibility to preserve the environment, is now given authority to rank the proposed sites in California. The CPUC, which focuses on questions of supply reliability, has final authority on approval of the proposed site. This decision can be made more or less independently of the CCC rankings. No single agency is now given a mandate to make trade-offs between environmental and energy supply concerns in considering the proposed site.

The second feature of multiparty decision processes illustrated in the California case is the importance of the structure of that process. Where 
there are conflicts of interest between different parties, the most effective power normally lies with the agency in the position to make the final decision. In the case of California, a key question considered in drafting the LNG Terminal Siting Act of 1977 was whether a conservation-minded group, such as the $\mathrm{CCC}$, or an agency concerned with energy needs such as the CPUC, would have final siting authority. Once the CPUC was chosen, the final decision regarding a site was constrained in different ways than if the $\mathrm{CCC}$ had been given this authority. The dynamics and the structure of the process had a critical bearing on the final decision.

But there are broader implications of the multiparty character of societal decision processes for low-probability events. Conflicts among parties are to be expected, since each stakeholder implicitly assigns different importance weights to the relevant attributes. Yet when one is concerned with low-probability events associated with a new technology (e.g., determining the chances and consequences of a severe accident of an LNG terminal), the analyses marshalled by the conflicting parties are not based on statistical analysis and tested assumptions. Instead, the analyses must rely on subjective probabilities and choices of assumption sets from a wide range of defensible scenarios [Lathrop and Linnerooth ${ }^{(24)}$ ]. The net result is that analysis does not play as important a role in such cases as it might if actuarial data were available on which to estimate probabilities and losses.

Arguments concerning low-probability events often involve the concept of acceptable risk. While the definition of acceptable risk assumes many guises [Lathrop ${ }^{(25)}$ ], a procedure like the following is often employed: a detailed risk analysis of a proposed site specifies the chances of death per year $(p)$ from LNG-related accidents to an individual at risk. If $p$ is below some threshold level, $p^{*}$, then the project is considered safe; if $p>p^{*}$ then it is not. For example, the FERC estimated the values of $p$ for three proposed California LNG terminal sites as ranging from $2 \times 10^{-7}$ to $8 \times 10^{-7}$. It pointed out that such risks are comparable to the risks from natural events such as lightning, tornadoes, and hurricanes, and concluded: "The staff believes that this level constitutes an acceptable risk to the public" [FERC $\left.{ }^{(26)}\right] .^{4}$ Yet of

\footnotetext{
${ }^{4}$ Keeney, et al. (39) utilize a particular $p^{*}$ in support of the acceptability of an LNG terminal in Matagorda Bay, Texas, They cite a rough criterion for risk acceptability of $p=10^{-7}$ suggested by Starr (40), and compare it to their estimated $p$ for the Matagorda Bay terminal of $2 \cdot 10^{-9}$.
}

course this form of argument does not in itself resolve safety debates, as the different parties can argue over what values of both $p$ and $p^{*}$ are appropriate for the case at hand.

\subsection{Role of Exogenous Events}

Another implication of the decision process associated with facility siting is that exogenous events can play an important role in triggering new coalitions and frequently new legislation. Each interested party focuses on limited information and uses the data in different ways. Due to the difficulty of resolving stakeholder conflicts, a particular event can cause a reversal or reinvestigation of a particular decision if the case has not been finalized. Consider the following four examples associated with LNG siting in the United States:

1. In 1973 an LNG tank in Staten Island, New York, exploded and the roof collapsed burying 40 workers. There was no LNG in the tank but it had seeped through the insulation and caused a huge fire. A result of this explosion was the increased concern with the dangers of LNG by Staten Island residents. The neighborhood organization called BLAST, which was formed a year before the accident, attracted considerable attention and interest because of the media coverage of the tank explosion. In the context of our descriptive model of choice, a new interested party played a key role because of a random event. What may have been a foregone deicison regarding the location of an LNG tank in Staten Island became problematical [Davis ${ }^{(27)}$ ].

2. The worst LNG accident occurred in 1944 when the storage tank operated by the East Ohio Gas Company in Cleveland ruptured, spilling LNG on adjacent streets and sewers. The liquid evaporated, the gas ignited and exploded, resulting in 128 deaths, 300 injuries, and approximately $\$ 7$ million in property damage. An investigation of this accident indicated that the tank failed because it was constructed of $3.5 \%$ nickel steel, which becomes brittle when it comes in contact with the extreme cold of LNG. All plants are now built with $9 \%$ nickel steel, aluminum, or concrete and the storage tanks are surrounded by dikes capable of containing the contents of the tank if a rupture occurs. This example illustrates the impact of a particular incident on the passage of new regulations. ${ }^{(27)}$ 
3. In December of 1976, the Los Angeles City Council voted to allow work to begin on an LNG terminal in San Pedro Bay. The following day an explosion ripped the oil tanker Sansinena in Los Angeles harbor leaving 9 dead and 50 injured. A week later the City Council commissioned a study as to the relative safety of the proposed site. They later approved the terminal. This explosion, although it had nothing to do with liquefied natural gas, alerted many Californians to the potential dangers of LNG. ${ }^{(27)}$

4. Until the publication of several worst case scenarios in 1976 on the possible consequences of a $\$ 300$ million terminal in Oxnard in California, there was general agreement by almost all stakeholders that Oxnard would be an acceptable site for an LNG terminal. At the time event the Sierra Club was in favor of this location. (They changed their feelings about Oxnard in 1977.) One worst case scenario indicated that a spill of $125,000 \mathrm{~m}^{3}$ of LNG from all five tanks on a tanker would cause a vapor cloud which would affect up to 70,000 people. Any resident could look on a map to determine whether the cloud covered his own house $\left[\mathrm{Ahern}^{(28)}\right]$. No estimate of a probability was attached to this scenario. The graphic depiction of these consequences generated a public reaction by groups of local citizens. The California legislature was influenced by this public reaction. One legislative staff member stressed that it was not possible to allow a site that would lead to a large number of deaths in a catastrophe. ${ }^{5}$ As a result, new siting regulations were passed stating that no more than an average of 10 people per square mile could be within one mile of the terminal and no more than 60 within four miles of the terminal. The President's National Energy Plan incorporated similar population guidelines which effectively ruled out any high density areas as candidates for an LNG terminal. This example illustrates how the context in which information is presented (e.g., a worst case scenario) may provoke strong reactions by interested parties and eventually lead to legislative changes.

\section{IMPROVING THE FACILITY SITING PROCESS: PRESCRIPTIVE ANALYSIS}

The above descriptive framework has revealed the set of difficult problems associated with the input

\footnotetext{
5 This comment was made to John Lathrop in an interview in Sacramento, California, in July 1980, regarding the siting process of an LNG terminal.
}

and interaction phases of the facility siting process. In this section we will explore possible ways of improving each of these phases of the decision process through more structured approaches. How successful these techniques are likely to be will vary with each specific problem and depends crucially on the resulting dynamics between the interested parties.

\subsection{The Input Phase}

Keeney ${ }^{(29)}$ has shown how decision analysis can help structure the siting decision but has focused primarily on the perspective of a single decision-maker rather than on more than one interested party with conflicting objectives and different information bases. Yet many of the general concepts proposed by Keeney are relevant for facilitating the input phase of our descriptive framework. It is particularly important to specify the set of decisions $\left\{D_{1}, \ldots, D_{n}\right\}$ that have to be made, how they relate to each other, and the relative importance each party gives to specific attributes. $^{6}$

Figure 2 is a representation of the interrelationship between parties, attributes, and alternatives for one decision, $D_{2}$. The figure is made up of three two-dimensional matrices. The upper left matrix relates alternatives, sites A, B, C, or no site, with attributes: supply interruption risk, risk to life and limb, land-use environmental degradation, and financial cost, respectively. The cell entries range from -- , a very unfavorable outcome, to ++ , a very favorable outcome.

This matrix, as it is drawn, implies that either there is a supra decision-maker who has characterized each site with respect to its ranking with regard to different attributes or there is consensus among the different interested parties on these rankings. In reality, there may be differences between how the relevant actors perceive each of the proposed sites. Thus, industry might view the cost to society of having no site as being very unfavorable (as actually shown in Fig. 2). Local interest groups might have a different view on the subject. In this case, each of these interested parties would construct their own alternativeattribute matrices. The shaded matrix on the lower left relates attributes to parties: government regulator (e.g., the CPUC or FERC), government coastal zone planner (e.g., the CCC), industry (e.g., the gas com-

\footnotetext{
${ }^{6}$ See Keeney and Raiffa (41) for a more detailed discussion of techniques for assessing the value tradeoffs of a decision maker among several attributes.
} 


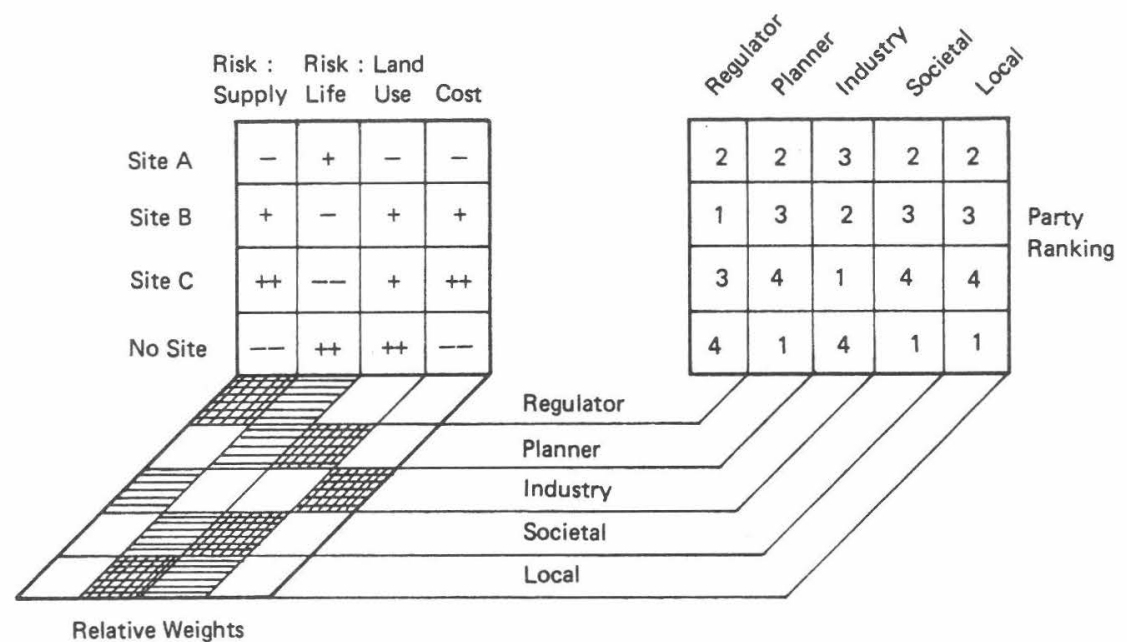

Fig. 2. Relationship between parties, attributes, and alternatives.

pany), societal interest group (e.g., the Sierra Club), and local interest group (e.g., neighboring landowners), respectively. The cell entries range from no shading, indicating little or no relative concern with the particular attribute by the party, to dark shading, indicating a great deal of concern. The right matrix could have been generated from more quantitative versions of the two left matrices. The cell entries reflect the relative rankings of each of the alternative sites by each of the interested parties.

The value of developing a structured approach to the problem, such as the matrix developed in Fig. 2 is that it points out differences between the parties. The diagram involves important simplifications in that it does not consider possible uncertainties as to which outcomes will result if different alternatives are chosen. It also does not consider the types of decision procedures which each of the parties are likely to utilize in determining the relative rankings between alternatives. These issues are more appropriately discussed in the interaction phase, to which we now turn.

\subsection{Interaction Phase}

Suppose that at the end of the input phase, we were able to arrive at a set of matrices, such as the one depicted in Fig. 2, where each of the five different interested parties had their own ranking between sites. One way to resolve differences would be to assign specific weights to each of the parties and choose the alternative which received the highest weighted score. This rather arbitrary way of resolving conflicts implies that there is some supra decisionmaker who has the authority to assign these weights. In reality, this is rarely the case. Instead, there is a process of bargaining, negotiation, and long-term delays induced by this conflict as illustrated by the California siting process. Several approaches have been proposed for reducing these conflicts which may be useful here.

\subsection{The Analytic Hierarchy Process}

Saaty ${ }^{(3)}$ has developed an approach for reconciling differences between parties. His analytic hierarchy process (AHP) is a systematic procedure for representing the elements of a problem through a hierarchical structure. By decomposing the problem into its smaller consitutent parts one only has to make simple pairwise comparison judgments to develop priorities in each hierarchy.

To illustrate how a hierarchy might be constructed for the LNG siting problem, consider the illustrative example presented in Fig. 2. We have represented the problem of choosing an appropriate site in terms of a four-level hierarchy, as depicted in Fig. 3. The first level is the single overall objective: which LNG site (if any) to select? The second level specifies the set of five interested parties and then lists the attributes which are considered to be important to each of these groups (Level 3). The lowest level consists of the set of alternatives available at a given point in time.

Priorities are established within each level of the hierarchy by assessing the relative importance of one 


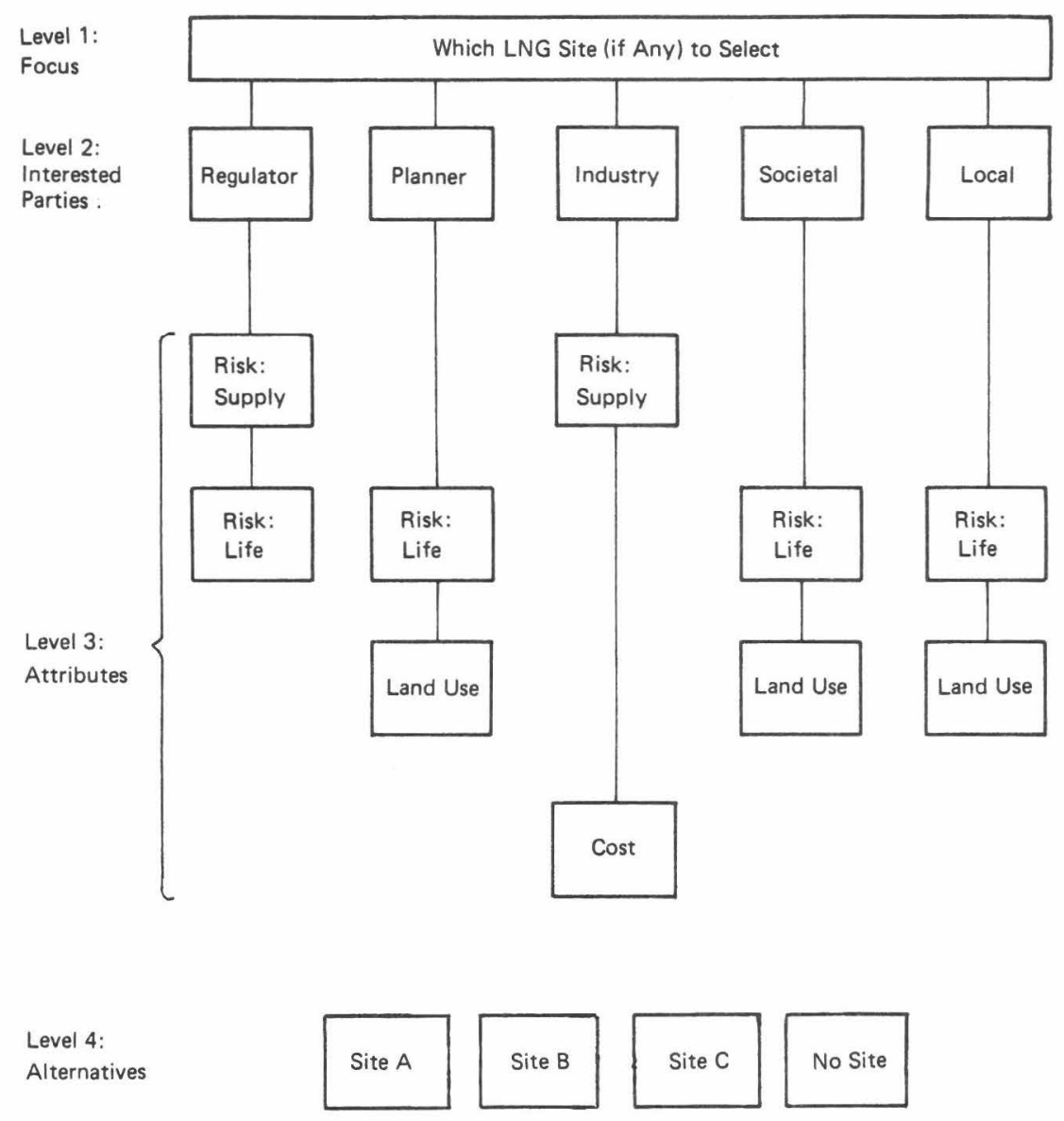

Fig. 3. Hierarchical structure for siting LNG facility.

element over the other in a pairwise comparison with respect to the criterion in the next higher level. For example, the importance of each of the interested parties with respect to the others (Level 2) will be determined in reference to the question of siting a facility (Level 1). A measurement theory is used to determine the priorities of the hierarchy based on the judgmental data provided by the decision-maker(s).

The potential success of the AHP for problems such as the siting of LNG facilities depends on the ability of the analyst to bring the relevant parties together, to elicit value judgments, and to reconcile differences between the different stakeholders with respect to assigning priority weights in pairwise comparisons. The LNG siting process in California reveals that each of the parties had their own objectives as well-as their own, possibly hidden, agenda. Some of the stakeholders may be reluctant to articulate their value structure for fear that they will lose some of their negotiating power as well as being publicly responsible for their positions. Ward Edwards ${ }^{(31)}$ encountered this latter problem in his study of evaluating school desegregation plans for Los Angeles. He noted that the interested parties in a societal decision problem are unlikely to reveal their value structure because this information then becomes public and groups would be accountable for numerical judgments. Whether the Saaty approach can overcome this problem with respect to such emotionally charged issues as LNG siting is still an open question. Even if each party is willing to provide relevant pairwise comparisons it is not clear how one utilizes this approach when there are significant differences between the weights each of them assigns.

\subsection{Examining Assumptions}

One way to understand and possibly reconcile differences between parties is to have each of them 
state the assumptions which they are utilizing in arriving at their conclusions. For example, industry would have to provide a rationale as to why it ranked site C as most desirable and the "no site" alternative as least desirable. Representatives of societal and local interest groups would have to defend their assumptions regarding their choices, which in this case were in the reverse order. Mitroff, Emshoff and $\mathrm{Kilmann}^{(32)}$ have proposed this type of dialectical approach to planning, as a way for each of the interested parties to better appreciate the other's position and perhaps arrive at some compromise. Majone ${ }^{(33)}$ also subscribes to such a process for decisions like that of facility siting, where the knowledge base is so poorly understood that this type of open discussion is likely to improve everyone's understanding of the problem.

Since there is limited statistical evidence which one can utilize for defending one's position it may be possible to undertake some type of sensitivity analysis to examine the consequences of changing specific assumptions. For example, suppose one is uncertain as to the magnitude of the methane cloud dispersion should there be a tank rupture of an LNG storage tank. By acknowledging this type of uncertainty and examining the consequences of locating plants in each of the three proposed locations, one can determine how important differences will be in terms of favoring one site over another. Even if this type of analysis does not reconcile differences, it will at least indicate to all the concerned parties on what basis one alternative is preferred over another.

\subsection{Utilizing Interactive Computer Modeling}

If it is impossible to bring the different interested parties together, then other techniques may have to be used. One of the most promising approaches is the use of interactive computer models for scenario generation. Each interested party would be able to construct his/her own scenario as to potential consequences of adopting one strategy over another, and determine the consequences of changes in assumptions of different parameters. The computer terminal plays the role of a giant calculator by processing new data and displaying the resulting outputs. Having already constructed different matrices, such as the one that comprises Fig. 2, each stakeholder would be in a position to articulate the potential consequences of say, locating an LNG terminal at several proposed sites or deciding not to construct a project. At this point, it would be possible to develop not only "worst case scenarios," but also less extreme situations, including the possibility that no accident occurs. ${ }^{7}$

There undoubtedly will be differences between the way interested parties view the situation, but the advantage of interactive-computer models is that these differences can then be examined in some detail to stimulate discussion between the interested parties. For example, scenarios could be generated which would permit one to analyze very uncertain data (such as probability and loss information) to determine their impact on relative rankings of sites.

For example, suppose one estimated the annual probability of a severe accident to be between $P_{1}$ to $P_{2}$ with losses ranging from $L_{1}$ to $L_{2}$. One could then develop scenarios which examine the relative merits of different alternatives as one changed these estimates. If specific sites were preferred over a wide range of values for probabilities and losses then this would simplify the choice process. If the rankings changed as $P_{i}$ and $L_{j}$ were varied, then this would suggest that these estimates be refined if possible.

\section{SUGGESTIONS FOR FUTURE RESEARCH}

The resolution of conflicts between interested parties may be extremely difficult even if one uses the more structured approaches proposed above. In fact, our descriptive framework suggests that interested parties may not want to get together to solve a particular problem unless they are forced to by existing legislation. Reconciliation of stakeholder conflicts is a time-consuming and threatening process since it involves detailed analysis on the part of each of the groups and acceptance of responsibility for one's actions. From a political standpoint, this may not always be the wisest thing to do. Hence, the above prescriptive suggestions can only be viewed as a starting point for developing a dialog between the parties. We need more research on designing policy instruments for reconciling differences between the vying groups.

One of the critical questions that needs to be addressed is how to design mechanisms for control-

7 This approach differs from decision analysis by focusing on individual scenarios rather than a probability distribution over outcomes. For a more detailed discussion of interactive computer models in a policy context see Kunreuther et al. (42). 
ling uncertain and unknown consequences of a particular decision. For example, in the case of the siting of an LNG facility we have limited statistical evidence to estimate probabilities and losses associated with a catastrophic accident and there is no experimental laboratory except the real world from which to obtain such data. Holling ${ }^{(18)}$ points out that there are two extreme reactions to this concern with an unknown and uncertain future: regulation and prediction. We have seen these two forces at work with respect to LNG siting in the form of new restrictions as to the location of a terminal regarding population density (regulation) and new design features of a terminal to prevent an accident (prediction). Interestingly enough, these changes in siting procedures were triggered by exogenous events and crises and were designed to reduce the chances that an undesirable event would occur in the future. Holling ${ }^{(18)}$ noted similar reactions to a variety of environmental problems which he and his colleagues at the Institute of Resource Ecology (University of British Columbia) examined through case studies.

Another area for future research is the design of policies to compensate parties at risk from the siting of a new facility. In the case of LNG there are many potential causes of an accident (e.g., ships, tanks, etc.), so it may be difficult to attribute fault to any one party. Furthermore, the ships, the liquefied natural gas, and the terminals are owned by different subsidiaries and companies. The local, national, and international jurisdictions make legal problems even more difficult. ${ }^{(27)}$

One possible direction for future study is the role of insurance as a way of protecting potential victims against potential property losses and physical injury. A General Accounting Office report of July $1978^{(34)}$ concluded that injured parties could not be fully compensated for a serious accident under present liability arrangements. What type of insurance arrangements are feasible between private firms and the industrial partners who are involved in the shipping, storage, and transmission of LNG? What role is appropriate for government to play with respect to offering protection? The Price Anderson Act as it applies to nuclear safety may provide some guidance in the design of some system of liability which involves joint private industry-federal government financial responsibility.

With respect to the more immediate consequences of siting a new facility, O'Hare ${ }^{(35)}$ has proposed a particular type of compensation scheme whereby each community proposed as a potential site determines a minimum level of per capita compensation so that it is willing to make a legal commitment to have the project in their backyard if the compensation is paid. The applicant would utilize this compensation as part of his calculations as to the relevant costs associated with locating the facilities in community A, B, or C. The final decision would then be made by the applicant taking into account the amount of compensation it would have to pay residents in each of these three localities.

This type of system would only be applied to potential sites that had satisfied specific governmental criteria related to safety and environmental risk. O'Hare recognizes that there will still be some individuals in a given community who will be compensated more than they need to be and others who will not be rewarded enough. $\mathrm{He}$ also recognizes that for such a system to be implemented there must be good information on the relevant costs, including an environmental impact statement, and that the system has to be designed to overcome the incentive to overbid.

Whether or not some type of compensation scheme is a useful policy prescription depends on the specifics of the situation. In this connection, it would be interesting to ask what type of payments would have been required to appease the citizens of Oxnard so that an LNG terminal could have been located there. What would the Sierra Club require in payments so that they would support a site which might have adverse environmental effects? These questions can only be answered in a real world problem context. They do reflect an increasing concern of economists and lawyers in dealing with windfalls or wipeouts from specific actions which involve the public sector. Hagman and Misczynski( ${ }^{(36)}$ in their comprehensive study of the subject believe that windfalls should be partially recaptured to help compensate for wipeouts. They propose a number of alternative mechanisms for ameliorating this problem ranging from special assessments to development permits. These types of policy instruments could also be investigated in the context of specific siting problems.

The final outcome is likely to represent some type of balance between the political constraints and economic criteria. As Wildavsky ${ }^{(37)}$ has pointed out:

The criterion of choice in politics and markets is not being right or correct as in solving a puzzle, but agreement based on interaction among partially opposed interests. (p. 133) 
The framework presented in this paper does not provide answers to the dilemma between economics and politics but it does help the analyst gain a better understanding of the causes of these conflicts. How one actually improves the process is a challenge for future problem-focused research.

\section{ACKNOWLEDGMENTS}

The research reported in this paper is supported by the Bundesministerium für Forschung und Technologie, F.R.G., contract no. 321/7591/RGB 8001. While support for this work is gratefully acknowledged, the views expressed are the authors' and not necessarily shared by the sponsor. This paper is part of a larger project a group of us at IIASA are undertaking with respect to siting decisions of $\mathrm{LNG}$ facilities.

We would like to acknowledge very helpful discussions with our IIASA colleagues; Hermann Atz, Joanne Linnerooth, Giandomenico Majone, Michiel Schwarz, Craig Sinclair, Michael Thompson, and James Vaupel. Randolph Deutsch, Jorg Finsinger, Ralph Keeney, Paul Kleindorfer, and Detlof von Winterfeldt provided helpful comments on an earlier draft of this paper. A more detailed discussion of the problems associated with siting $\mathrm{LNG}$ facilities in European countries and the United States appears in H. Kunreuther, J. Linnerooth, and R. Starnes Liquefied Energy Gas Facility Siting, Proceedings of an IIASA Task Force Meeting, 23-26 September 1980, (IIASA, Laxenburg, Austria, in press).

\section{REFERENCES}

1. W. Ahern, "The Role of Technical Analyses in California Energy Facility Siting" in H. Kunreuther, J. Linnerooth, and R. Starnes, eds. Liquefied Energy Gas Facility Siting Proceedings of an IIASA Task Force Meeting, 23-26 September 1980 (in press).

2. R. Deutsch," "Siting an L.N.G. Facility in California: The Regulatory Framework and the Factors Involved in the Decision Making Process" in H. Kunreuther, J. Linnerooth, and R. Starnes, eds., Liquefied Energy Gas Facility Siting Proceedings of an IIASA Task Force Meeting, 23-26 September 1980, (in press).

3. J. Linnerooth, "A Short History of the California LNG Terminal," IIASA WP-80-155, Laxenburg, Austria (October 1980).

4. J. W. Lathrop, "Decision Making in LNG Terminal Siting: The California Case" in H. Kunreuther, J. Linnerooth, and R. Starnes, eds., Liquefied Energy Gas Facility Siting Proceedings of an IIASA Task Force Meeting, 23-26 September 1980 (in press).
5. B. Fischhoff, P. Slovic, and S. Lichtenstein, "Lay Foibles and Expert Fables in Judgments about Risk" in T. O'Riordan and R. K. Turner, eds., Progress in Resource Management and Environment Planning, Vol. 3 Wiley, (Chichester, in press).

6. A. Tversky and D. Kahneman, "Judgment Under Uncertainty: Heuristics and Biases," Science 185, 1124-31 (1974).

7. A. Tversky and D. Kahneman, "The Framing of Decisions and the Psychology of Choice," Science 211, 453-58 (1981).

8. J. Hershey, H. Kunreuther, and P. Schoemaker, "Sources of Bias in Assessment Procedures for Utility Functions," Management Science (in press).

9. W. Fairley, "Evaluating the 'Small' Probability of a Catastrophic Accident from the Marine Transport of Liquefied Natural Gas," In Fairley and Mosteller, eds., Statistics and Public Policy Addison-Wesley, (Reading, Mass, 1977).

10. J. March, "Bounded Rationality, Ambiguity and the Engineering of Choice," Bell Journal of Economics 9, 587-608 (Spring 1978)

11. C. Lindblom, "The Science of Muddling Through," Public Administration Review 19, 79-88 (1959).

12. D. Braybrooke and C. Lindblom, A Strategy of Decision (The Free Press, New York, 1963).

13. R. Cyert and J. March, A Behavorial Theory of the Firm, Prentice Hall, (Englewood Cliffs, N.J., 1963).

14. J. Bettmann, An Information Processing Theory of Consumer Choice, Addison Wesley, (Reading, Mass., 1979).

15. A. Tversky and D. Kahneman, "Availability: A Heuristic for Judging Frequency and Probability," Cognitive Psychology, 5, 207-232 (1973).

16. H. Kunreuther, R. Ginsberg, L. Miller, P. Sagi, P. Slovic, B. Borkan, and N. Katz, Disaster Insurance Protection: Public Policy Lessons, New York, Wiley and Sons (1978).

17. J. March and J. Olsen, Ambiguity and Choice in Organizations, Universtetsforlaget (Bergen, Norway, 1976).

18. C. S. Holling, "Resilience in the Unforgiving Society," Working Paper R-24, Vancouver Institute of Resource Ecology (March 1981).

19. J. Walker, "Setting the Agenda in the U.S. Senate: A Theory of Problem Selection," British Journal of Political Science, 7. 423-445 (1977).

20. J. Lawless, Technology and Social Shock, (Rutgers University Press, New Brunswick, N.J., 1977).

21. J. Jackson and H. Kunreuther, "Low Probability Events and Determining Acceptable Risk: The Case of Nuclear Regulation," IIASA PP-81-7, Laxenburg, Austria (1981).

22. Office of Technology Assessment (OTA), Transportation of Liquefied Natural Gas, Washington, D.C., (1977).

23. DOE/ERA, Opinion and Order on Importation of Liquefied Natural Gas.

24. J. W. Lathrop and J. Linnerooth, "The Role of Risk Assessment in a Political Decision Process," in P. Humphreys and A. Vari (eds), Analayzing and Aiding Decision Processes, Amsterdam, North Holland, (forthcoming).

25. J. W. Lathrop, "Measuring Social Risk and Determining its Acceptability," in D. Fischer, ed., Two Blowouts in the North Sea (Pergamon, Oxford, in press).

26. Federal Energy Regulatory Commission, "Western LNG Project, Final Environmental Impact Statement," FERC/EIS$0002 F$, Vol. III (1978).

27. L. N. Davis, Frozen Fire, (Friends of the Earth, 1979).

28. W. Ahern, "California Meets the LNG Terminal," Coastal Zone Management Journal 7, 185-221 (1980).

29. R. Keeney, Siting Energy Facilities (Academic Press, New York, 1980)

30. T. Saaty, The Analytic Hierarchy Process, (McGraw-Hill, New York, 1980)

31. W. Edwards, "Reflections on and Criticisms of a Highly Political Multi-attitude Utility Analysis," in L. Cobb and R. 
Thrall eds., Mathematical Frontiers of the Social and Policy Sciences, (Westview Press, Boulder, 1981 pp. 157-189.)

32. I. Mitroff, J. Emshoff, and R. Kilmann, "Assumptional Analysis: A Methodology for Strategic Problem Solving," Management Science 6, 583-593 (1979).

33. N. Majone, "Process and Outcome in Regulatory Decisions," American Behavioral Scientist 22, 561-583 (1979).

34. General Accounting Office, "Liquified Energy Gases Safety," Report to the Congress, EMD-78-28 Volume 1. Washington D.C. (1978).

35. M. O’Hare, "Not On My Block You Don't: Facility Siting and the Strategic Importance of Compensation," Public Policy, 25, 409-58 (1977).

36. D. Hagman and D. Misczynski, Windfalls for Wipeouts, (Chicago, American Society of Planning Officials, 1978).
37. A. Wildavsky, "Rationality in Writing: Linear and Curvilinear," Journal of Public Policy, 1, 125-40 (1981).

38. H. Kunreuther, J. Lathrop, and J. Linnerooth, "A Descriptive Model of Choice for Siting Facilities: The Case of the California LNG Terminal," IIASA WP-82-18, Laxenburg, Austria.

39. R. Keeney, R. Kulkarni and K. Nair, "A Risk Analysis of an LNG Terminal,” Omega 7, 191-205 (1979).

40. C. Starr, "Social Benefit versus Technological Risk," Science 165, 1232-38 (1969).

41. R. Keeney and H. Raiffa, Decisions with Multiple Objectives, (Wiley, New York, 1976).

42. H. Kunreuther, J. Lepore, L. Miller, J. Vinso, J. Wilson, B. Borkan, B. Duffy, and N. Katz, An Interactive Modeling System for Disaster Policy Analysis (University of Colorado Press, Institute of Behavioral Science, 1978). 



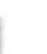

